\title{
Primary jejunal gastrinoma: a case report and review of the literature
}

\author{
Kevin A. Wang ${ }^{1}$, Yenn-Hwei Chou ${ }^{1 *}$, Shu-Han Huang ${ }^{2}$ and Tong-Jong Chen ${ }^{2}$
}

\begin{abstract}
Background: Primary jejunal gastrinomas are exceedingly rare, and data for long-term follow-up is limited. Until now, only six cases of gastrinomas arising from the jejunum have been reported in the English literature.

Case Presentation: Presented is a case of a primary gastrinoma located in the proximal jejunum. After surgical resection of the tumor, eugastrinemia was quickly achieved and after a 10-year follow-up period, the patient was still disease-free.

Conclusions: This case report demonstrates that surgical resection of a primary jejunal gastrinoma without evidence of metastasis can be curative, with a good long-term prognosis.
\end{abstract}

Keywords: Zollinger-Ellison syndrome, Gastrinoma, Jejunum

\section{Background}

A gastrinoma is a non-beta islet cell tumor which secretes gastrin. The hypergastrinemic state caused by a gastrinoma results in multiple recurrent and often refractory ulcers in the gastrointestinal tract and is known as Zollinger-Ellison syndrome (ZES). In 1955, ZES was originally reported with the presenting triad of recurrent peptic ulceration, hypersecretion of gastric acid, and the presence of a non-beta islet cell tumor of the pancreas [1]. Since then, it has been well-documented that most primary gastrinomas are found mainly in the duodenum, pancreatic head, or lymph nodes within the traditional gastrinoma triangle which is demarcated by the junction of the cystic duct and common bile duct, junction of the second and third portion of the duodenum, and the junction between the neck and body of the pancreas [2].

However, there have been reported cases of gastrinomas outside of these areas, which have been called ectopic gastrinomas. About $5.6 \%$ of patients have a primary gastrinoma located in an ectopic site [3]. Primary jejunal gastrinomas are exceedingly rare, and data for long-term follow-up is limited. Until now, only six cases of gastrinomas arising from the jejunum have been

\footnotetext{
* Correspondence: M001010@ms.skh.org.tw

'Division of General Surgery, Department of Surgery, Shin Kong Wu Ho-Su Memorial Hospital, No. 95, Wenchang Rd., Shilin Dist., Taipei 11101, Taiwan, Republic of China

Full list of author information is available at the end of the article
}

reported in the English literature [3-7]. Presented is a case of a primary gastrinoma located in the proximal jejunum, which is a possible diagnosis when a jejunum tumor is detected by radiographic examination. Ten years after segmental resection of the jejunum containing the gastrinoma, the patient was still eugastrinemic and asymptomatic, and there was no evidence of tumor recurrence.

\section{Case presentation}

In September 2003, a 34-year-old male patient presented at the Department of Surgery at Shin Kong Wu Ho-Su Memorial Hospital (Taipei, Taiwan) with abdominal fullness and discomfort that had gradually developed over the past year. Upon further review, the patient had an 8 -year history of heartburn which was only slightly relieved by antacids. Bowel habits were normal without mention of tarry or bloody stool. Also, he did not notice recent body weight loss.

Abdominal ultrasound in September of 2003 showed an abdominal mass in the left upper quadrant of his abdomen. An abdominal computed tomography (CT) confirmed a left upper quadrant abdominal mass (approximately $7 \mathrm{~cm} \times 6 \mathrm{~cm} \times 4 \mathrm{~cm}$ ) near the proximal jejunum (Fig. 1). Esophagogastroduodenoscopy and small-bowel endoscopy revealed several esophageal, gastric, duodenal, and upper jejunal ulcers (Fig. 2). Serum gastrin levels were elevated $(451.00 \mathrm{pg} / \mathrm{mL}$; normal range $30-100 \mathrm{pg} / \mathrm{mL}$ ). Serum tumor markers 


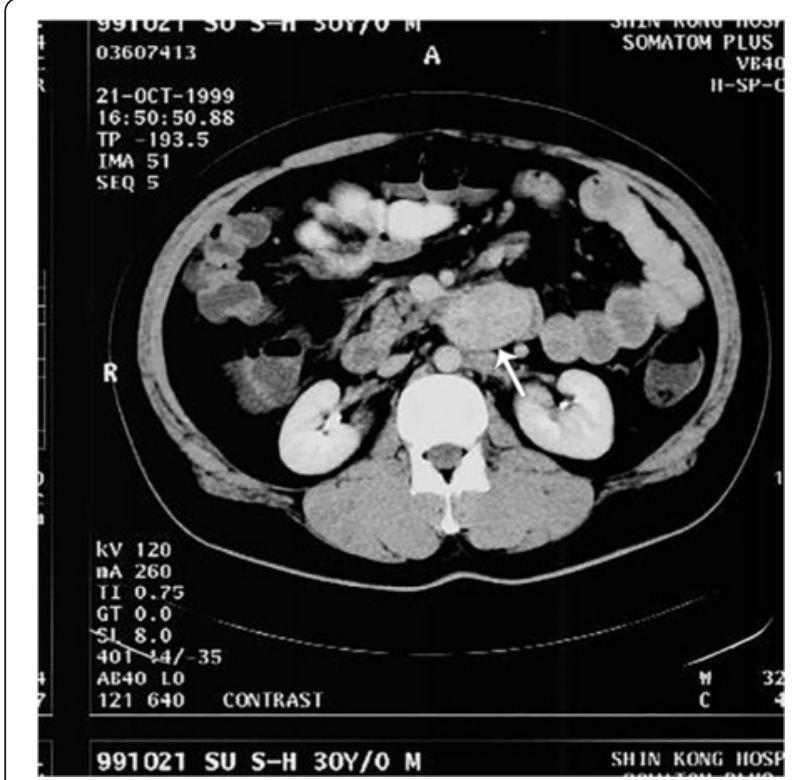

Fig. 1 Contrast abdominal computed tomography showing a $7 \mathrm{~cm} \times 6 \mathrm{~cm} \times 4 \mathrm{~cm}$ mass in the proximal jejunum (white arrow) including alpha-fetoprotein (AFP), carcinoembryonic antigen (CEA), and carbohydrate antigen 19-9 (CA 19-9) were within normal limits. The presence of multiple ulcers, ulcers distal to the first portion of the duodenum, refractory symptoms of gastroesophageal reflux disease, and elevated fasting serum gastrin levels raised the suspicion of Zollinger-Ellison syndrome. Endoscopic ultrasound (EUS) was performed to localize a possible tumor in the gastrinoma triangle but was unable to identify any tumor.

An exploratory laparotomy was performed. At surgery, a large tumor was identified in the wall of the proximal jejunum, approximately $3 \mathrm{~cm}$ distal to the ligament of Treitz. Thorough exploration of the abdomen, including the liver, small intestine, pancreas, stomach, duodenum, mesentery, and retroperioneal regions in the upper abdomen and concomitant intraoperative ultrasonography (US) did not reveal any other tumors. Segmental resection of the upper jejunum, including a $7 \mathrm{~cm} \times 6 \mathrm{~cm} \times 4 \mathrm{~cm}$ tumor just distal to the ligament of Treitz, was done, and subsequent jejunal-jejunal end-to-end anastomosis was performed.

Pathological findings of the jejunal tumor showed a neuroendocrine tumor consistent with gastrinoma. Microscopically, the tumor was composed of relatively uniform cells having centrally located nuclei and eosinophilic cytoplasm (Fig. 3). The tumor cells were arranged

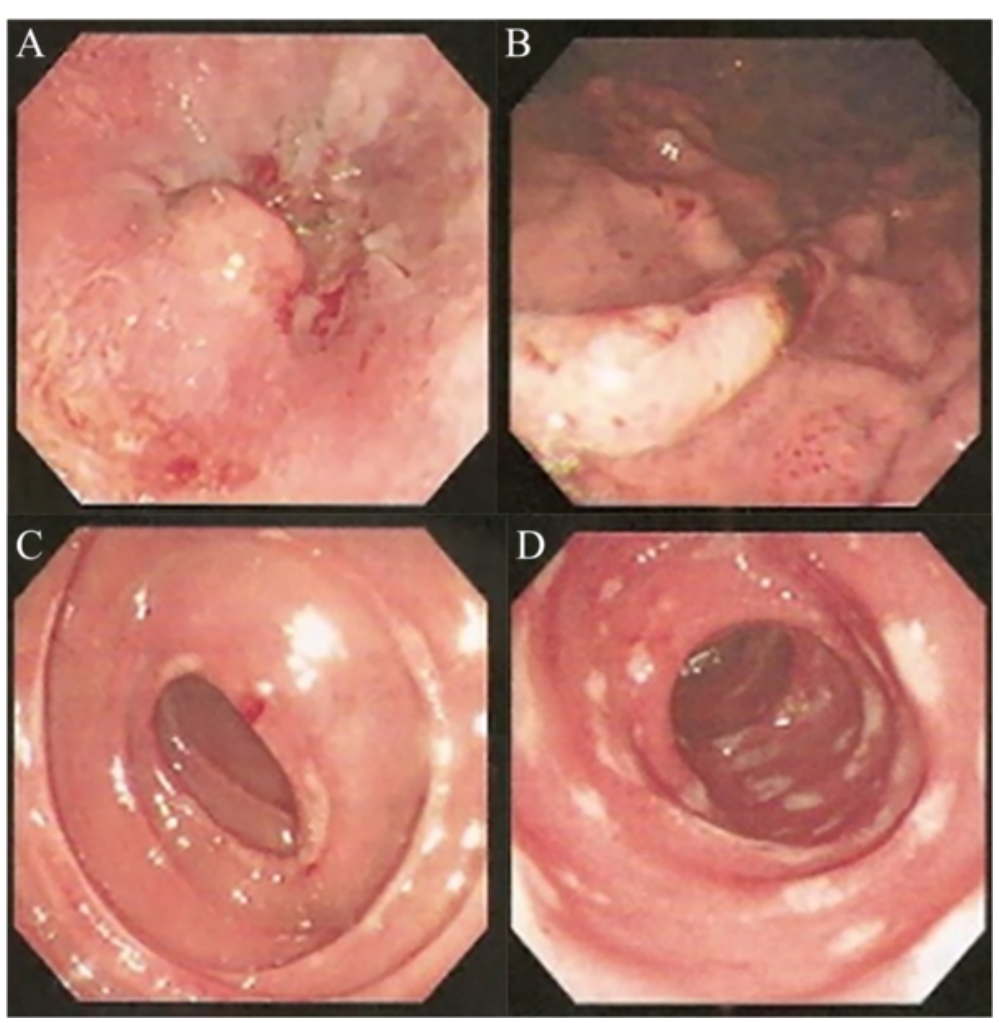

Fig. 2 Findings of esophagogastroduodenoscopy and small-bowel endoscopy. a Circumferential reflux esophagitis with superficial ulceration was observed in the distal esophagus near the gastroesophageal junction. b Gastric ulcers with hemorrhage were noted. c Multiple erosions were found in the duodenum. d Several upper jejunal ulcers were also noted 


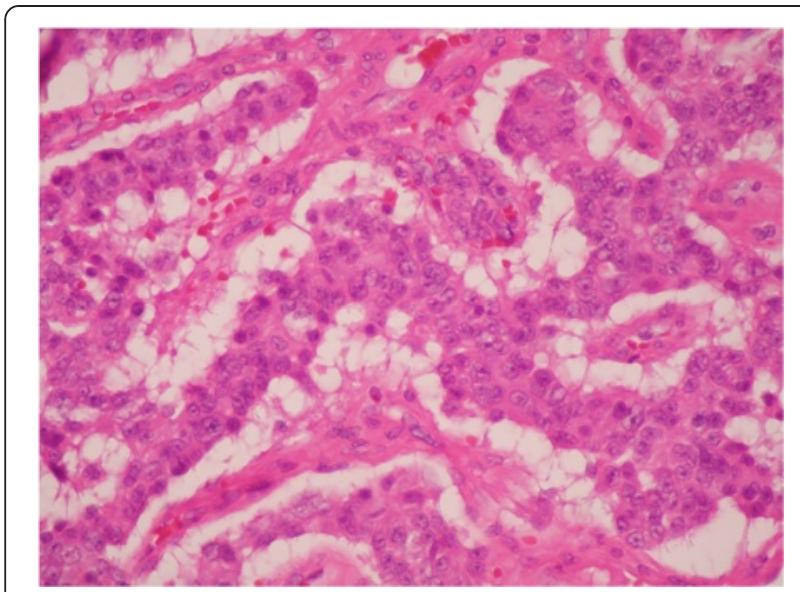

Fig. 3 Hematoxylin and eosin stain $(\times 400)$. The tumor had relatively uniform cells having centrally located nuclei and eosinophilic cytoplasm

in trabecular and gyriform fashions (Fig. 4). The mitotic index was low, and no tumor necrosis was found. On immunohistochemical studies, the tumor cells were positive for gastrin (Fig. 5).

On the fifth postoperative day, his fasting serum gastrin had decreased to $65.8 \mathrm{pg} / \mathrm{mL}$. He was discharged 9 days postoperatively in fair condition without any complications. The patient was regularly followed up, and over 10 years after surgery, the patient remains free of acid regurgitation and abdominal discomfort and is in good health. Current gastrin levels are normal $(75.60 \mathrm{pg} /$ $\mathrm{mL}$ ), esophagogastroduodenoscopy revealed no ulcers, and recent $\mathrm{CT}$ and magnetic resonance imaging (MRI) showed no signs of recurrent tumors.

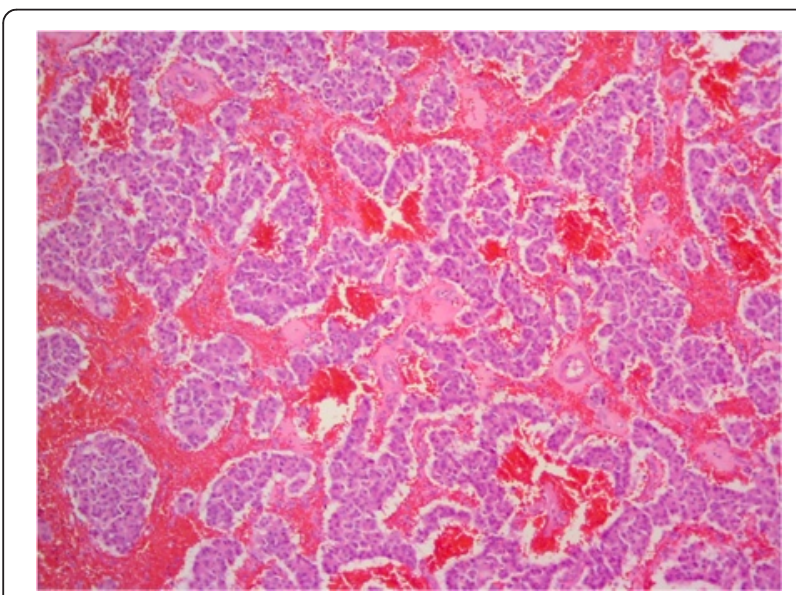

Fig. 4 Hematoxylin and eosin stain $(\times 100)$. The tumor cells were arranged in trabecular and gyriform fashions

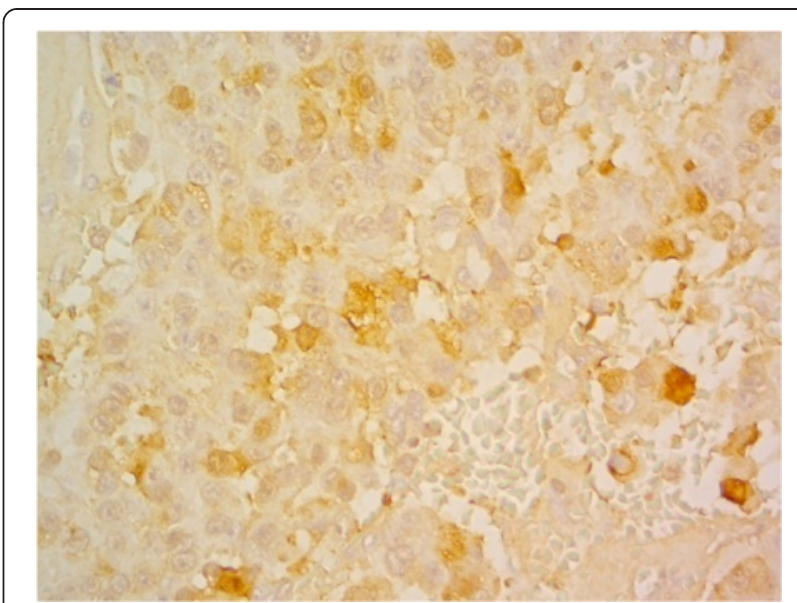

Fig. 5 Gastrin stain (×400). Immunohistochemical stains were positive for gastrin

\section{Discussion}

Primary jejunal gastrinomas are exceedingly rare, and data for long-term follow-up is limited. To our knowledge, only six cases of gastrinomas originating from the jejunal wall have been reported in the English literature to date (Table 1) [3-7].

Gastrinomas of the jejunum are usually small in size, with a reported diameter of $0.5-3 \mathrm{~cm}[4,5]$. There has only been one case where the tumor was identified preoperatively by combined imaging studies [5]. Preoperative imaging studies have failed to identify a primary tumor in the other reported cases. The unique feature of our case is that the tumor was large in size, and may be the largest tumor reported to date. Preoperative ultrasound and abdominal CT correctly localized the ectopic gastrinoma.

Although gastrinomas tend to be slow growing, 60 to $90 \%$ of them were associated with metastases [8-10]. Like other neuroendocrine tumors, malignancy cannot be established cytologically, but is determined by the presence of metastases as well as vascular or lymphatic invasion [11]. Larger gastrinomas are more likely to metastasize; liver and regional lymph nodes are the most common sites of metastases. Our case is unusual in that the tumor was large in size, yet there is no evidence of distant metastasis.

Many of the gastrinomas are small in size, which makes preoperative localization highly challenging. Furthermore, since the jejunum is not located within the gastrinoma triangle, this unexpected localization makes the diagnosis difficult. A number of tests are used to localize gastrinomas. CT scan, MRI, and ultrasound are used widely as the initial methods for localizing gastrinoma and are excellent for visualization of larger tumors. Somatostatin receptor scintigraphy (SRS) has a high sensitivity for assessing the extent of the disease. In 
Table 1 Reported cases of jejunal gastrinomas including location, surgical procedure, follow-up period, and outcome

\begin{tabular}{|c|c|c|c|c|c|c|c|}
\hline Author, year & $\begin{array}{l}\text { Sex/age } \\
\text { (years) }\end{array}$ & $\begin{array}{l}\text { FSG level } \\
(\mathrm{pg} / \mathrm{mL})\end{array}$ & Location of jejunal gastrinoma & $\begin{array}{l}\text { Size } \\
(\mathrm{cm})\end{array}$ & Procedure & Follow-up & Outcome \\
\hline \multirow{2}{*}{$\begin{array}{l}\text { Norton } \\
\text { et al. } 1986\end{array}$} & $M / 66$ & 5650 & Around the ligament of Treitz & 3 & Tumor excision & 6 months & No recurrence \\
\hline & $F / 35$ & 460 & Around the ligament of Treitz & 0.5 & Tumor excision & 3 months & $\begin{array}{l}\text { Abnormal FSG } \\
\text { at } 3 \text { months }\end{array}$ \\
\hline $\begin{array}{l}\text { Antonioli } \\
\text { et al. } 1987\end{array}$ & $F / 46$ & $730-980$ & $\begin{array}{l}5 \text { nodules in the jejunal wall, } \\
10 \mathrm{~cm} \text { distal to the ligament } \\
\text { of Treitz, with adjacent } \\
\text { mesenteric lymph node } \\
\text { metastasis }\end{array}$ & $0.4-3$ & $\begin{array}{l}\text { Partial resection of } \\
\text { involved jejunum } \\
\text { and mesentery }\end{array}$ & 42 months & $\begin{array}{l}\text { Alive and } \\
\text { remained } \\
\text { eugastrinemic }\end{array}$ \\
\hline $\begin{array}{l}\text { Katoh et al. } \\
1990[6]\end{array}$ & $M / 25$ & 764 & $\begin{array}{l}\text { A primary gastrinoma in the jejunal } \\
\text { wall just distal to the ligament of } \\
\text { Treitz. Two more tumors in adjacent } \\
\text { jejunal mesentery. Multiple liver } \\
\text { metastases }\end{array}$ & NP & $\begin{array}{l}\text { Excision of jejunum } \\
\text { tumors + remnant } \\
\text { gastrectomy }\end{array}$ & 10 years & $\begin{array}{l}\text { Alive and in } \\
\text { stable condition }\end{array}$ \\
\hline $\begin{array}{l}\text { Nishiwaki et al. } \\
1992[7]\end{array}$ & $M / 63$ & $787-1913$ & $\begin{array}{l}\text { A primary gastrinoma in the } \\
\text { submucosa of the jejunum. A lymph } \\
\text { node metastasis }(1.5 \mathrm{~cm}) \text { in the } \\
\text { jejunal mesentery } 5 \mathrm{~cm} \text { distal to } \\
\text { the ligament of Treitz }\end{array}$ & NP & $\begin{array}{l}\text { Partial resection of jejunum } \\
\text { and pancreatocduodenectomy } \\
\text { (on the suspicion of multiple } \\
\text { primary sites) }\end{array}$ & 7 months & $\begin{array}{l}\text { Alive and remained } \\
\text { eugastrinemic }\end{array}$ \\
\hline $\begin{array}{l}\text { Wu et al. } \\
1997[3]\end{array}$ & $M / 35$ & 460 & $\begin{array}{l}\text { Jejunum (distance from the ligament } \\
\text { of Treitz not mentioned) }\end{array}$ & NP & $\begin{array}{l}\text { Tumor resection by } \\
\text { enucleation }\end{array}$ & 134 months & $\begin{array}{l}\text { Elevated FSG at } \\
2 \text { years, local } \\
\text { recurrence at } 11 \text { years }\end{array}$ \\
\hline
\end{tabular}

$M$ male, $F$ female, $F S G$ fasting serum gastrin, $N P$ not provided

recent years, SRS has become the imaging study of choice for identifying primary tumors and metastatic lesions in ZES [12-15]. However, the sensitivity of SRS to detect gastrinomas is highly dependent on its size, ranging from $30 \%$ for gastrinomas smaller than $1.1 \mathrm{~cm}$ to $96 \%$ for gastrinomas larger than $2 \mathrm{~cm}$ [15]. EUS has a high sensitivity for detection of pancreatic gastrinomas, ranging from 75 to $100 \%[16,17]$. However, EUS is not as accurate in detecting duodenal gastrinomas [18]. These imaging studies should be used in conjunction to achieve optimal preoperative assessment of the gastrinoma. It is important to note that smaller tumors (less than $1 \mathrm{~cm}$ ) may often be missed and may require the use of IOUS to facilitate localization of small lesions that were not readily visible on preoperative studies. Current transducers can detect lesions as small as $2 \mathrm{~mm}$ [19]. In our case, preoperative abdominal CT and EUS and intraoperative US were use for localization of the gastrinoma and rule out metastatic disease. SRS was not performed because it was not available at our institute at the time of diagnosis in 2003.

The discovery of a gastrinoma in the jejunum raises the question of whether the tumor is a primary or metastatic lesion. Exhaustive preoperative imaging as well as careful surgical exploration during laparotomy including intraoperative ultrasound revealed no additional lesions. Thus, the large jejunal tumor was considered to be the primary lesion. Still, it was possible that an occult primary lesion was missed by EUS, surgical exploration, and intraoperative ultrasound. However, plasma gastrin level normalized shortly after the excision of the tumor. Over 10 years after surgery, the patient is still eugastrinemic, and there is no evidence of tumor recurrence in long-term follow-up. Based on these findings, it is apparent that the jejunal tumor is a solitary primary gastrinoma.

The current treatment of sporadic, resectable, nonmetastatic gastrinomas is early surgical exploration and surgical resection. Reviews have stated that for sporadic gastrinomas, the initial postoperative cure rate is approximately $50-60 \%$, and the long-term cure rate is $35-40 \%$ [20-22]. There are a limited number of studies addressing the long-term follow-up of ectopic gastrinomas. Wu el al. treated eight patients with ectopic gastrinomas from 1982 to 1997, seven patients were cured biochemically after resection, and five patients were cured with a mean follow-up of 7.5 years (range, 0.411.7 years) [3]. In our case, after surgical excision of the gastrinoma located in the jejunum as the lone method of treatment, the patient was still eugastrinemic and asymptomatic without tumor recurrence at 10-year follow-up. Among the six reported cases of gastrinomas originating from the jejunal wall, only three cases reported a follow-up period of more than 3 years $[3,5,6]$. Antonioli et al. reported a case with gastrinomas in the jejunal wall with metastatic lymph nodes in the adjacent mesentery. After resection of the involved jejunum and mesentery, she remained eugastrinemic 3 years after operation [5]. Katoh et al. reported a case of gastrinoma in the jejunum and jejunal mesentery with multiple liver 
metastases. Ten years after tumor resection, the patient is alive and there was stabilization of liver metastasis [6]. $\mathrm{Wu}$ et al. reported a case of primary jejunal gastrinoma treated by enucleation, who had biochemical recurrence at 2 years after surgery and local recurrence detected by SRS at 11 years after surgery [3].

\section{Conclusions}

Although primary jejunal gastrinomas are rare occurrences, it should be considered during the differential diagnosis of jejunal tumors if classic symptoms, such as uncontrolled reflux, non-healing mucosal ulcers or diarrhea are present. Here, we report an extremely rare case of a primary jejunal gastrinoma in which the tumor may be the largest reported to date. Over 10 years after segmental resection of the jejunum containing the gastrinoma, the patient is still eugastrinemic and asymptomatic with no evidence of tumor recurrence.

\section{Consent}

Written informed consent was obtained from the patient for publication of this Case report and any accompanying images. A copy of the written consent is available for review by the Editor-in-Chief of this journal.

\section{Abbreviations}

ZES: Zollinger-Ellison Syndrome; CT: computed tomography; AFP: alphafetoprotein; CEA: carcinoembryonic antigen; CA 19-9: carbohydrate antigen 19-9; EUS: endoscopic ultrasound; US: ultrasonography; MRI: magnetic resonance imaging; SRS: somatostatin receptor scintigraphy.

\section{Competing interests}

The authors declare that they have no competing interests.

\section{Authors' contributions}

All authors read and approved the final manuscript. KW wrote the manuscript, YC performed the surgery and edited the manuscript, and SH and TC provided pathological data.

\section{Author details}

'Division of General Surgery, Department of Surgery, Shin Kong Wu Ho-Su Memorial Hospital, No. 95, Wenchang Rd., Shilin Dist., Taipei 11101, Taiwan, Republic of China. ${ }^{2}$ Department of Pathology and Laboratory Medicine, Shin Kong Wu Ho-Su Memorial Hospital, No. 95, Wenchang Rd., Shilin Dist., Taipei 11101, Taiwan, Republic of China.

Received: 20 June 2015 Accepted: 2 November 2015 Published online: 06 November 2015

\section{References}

1. Zollinger RM, Ellison EH. Primary peptic ulcerations of the jejunum associated with islet cell tumors of the pancreas. Ann Surg. 1955;142(4):709-23. discussion, 24-8.

2. Stabile BE, Morrow DJ, Passaro Jr E. The gastrinoma triangle: operative implications. Am J Surg. 1984;147(1):25-31.

3. Wu PC, Alexander HR, Bartlett DL, Doppman JL, Fraker DL, Norton JA, et al. A prospective analysis of the frequency, location, and curability of ectopic (nonpancreaticoduodenal, nonnodal) gastrinoma. Surgery. 1997;122(6):1176-82.

4. Norton JA, Doppman JL, Collen MJ, Harmon JW, Maton PN, Gardner JD, et al. Prospective study of gastrinoma localization and resection in patients with Zollinger-Ellison syndrome. Ann Surg. 1986;204(4):468-79.
5. Antonioli DA, Dayal Y, Dvorak AM, Banks PA. Zollinger-Ellison syndrome. Cure by surgical resection of a jejunal gastrinoma containing growth hormone releasing factor. Gastroenterology. 1987;92(3):814-23.

6. Katoh H, Yabana T, Yachi A, Tanabe T. Malignant Zollinger-Ellison syndrome. Stabilization of liver metastasis after gastrectomy with resection of primary tumor. Am Surg. 1990;56(6):360-3.

7. Nishiwaki H, Kawazoe Y, Yamashita T, Satake K, Sowa M. A case of jejunal gastrinoma diagnosed by percutaneous transhepatic portal venous sampling. Gastroenterol Jpn. 1992;27(3):405-10.

8. Kloppel G, Anlauf M. Gastrinoma-morphological aspects. Wien Klin Wochenschr. 2007;119(19-20):579-84. doi:10.1007/s00508-007-0885-1.

9. Jensen RT, Niederle B, Mitry E, Ramage JK, Steinmuller T, Lewington V, et al. Gastrinoma (duodenal and pancreatic). Neuroendocrinology. 2006;84(3):173-82. doi:10.1159/000098009.

10. Gibril F, Jensen RT. Advances in evaluation and management of gastrinoma in patients with Zollinger-Ellison syndrome. Curr Gastroenterol Rep. 2005:7(2):114-21.

11. Abood GJ, Go A, Malhotra D, Shoup M. The surgical and systemic management of neuroendocrine tumors of the pancreas. Surg Clin North Am. 2009;89(1):249-66. doi:10.1016/j.suc.2008.10.001.

12. Gibril F, Jensen RT. Diagnostic uses of radiolabelled somatostatin receptor analogues in gastroenteropancreatic endocrine tumours. Dig Liver Dis. 2004;36 Suppl 1:S106-20.

13. Termanini B, Gibril F, Reynolds JC, Doppman JL, Chen CC, Stewart CA, et al. Value of somatostatin receptor scintigraphy: a prospective study in gastrinoma of its effect on clinical management. Gastroenterology. 1997;112(2):335-47.

14. Norton JA, Jensen RT. Current surgical management of Zollinger-Ellison syndrome (ZES) in patients without multiple endocrine neoplasia-type 1 (MEN1). Surg Oncol. 2003;12(2):145-51.

15. Alexander HR, Fraker DL, Norton JA, Bartlett DL, Tio L, Benjamin SB, et al. Prospective study of somatostatin receptor scintigraphy and its effect on operative outcome in patients with Zollinger-Ellison syndrome. Ann Surg. 1998;228(2):228-38.

16. Anderson MA, Carpenter S, Thompson NW, Nostrant TT, Elta GH, Scheiman $J M$. Endoscopic ultrasound is highly accurate and directs management in patients with neuroendocrine tumors of the pancreas. Am J Gastroenterol. 2000;95(9):2271-7. doi:10.1111/j.1572-0241.2000.02480.x.

17. Rosch T, Lightdale CJ, Botet JF, Boyce GA, Sivak Jr MV, Yasuda K, et al. Localization of pancreatic endocrine tumors by endoscopic ultrasonography. N Engl J Med. 1992;326(26):1721-6. doi:10.1056/nejm199206253262601.

18. Norton JA, Jensen RT. Resolved and unresolved controversies in the surgical management of patients with Zollinger-Ellison syndrome. Ann Surg. 2004;240(5):757-73.

19. Guimaraes CM, Correia MM, Baldisserotto M, de Queiroz Aires EP, Coelho JF. Intraoperative ultrasonography of the liver in patients with abdominal tumors: a new approach. J Ultrasound Med. 2004;23(12):1549-55.

20. Morrow EH, Norton JA. Surgical management of Zollinger-Ellison syndrome; state of the art. Surg Clin North Am. 2009;89(5):1091-103. doi:10.1016/j.suc.2009.06.018.

21. Norton JA, Alexander HR, Fraker DL, Venzon DJ, Gibril F, Jensen RT. Does the use of routine duodenotomy (DUODX) affect rate of cure, development of liver metastases, or survival in patients with Zollinger-Ellison syndrome? Ann Surg. 2004;239(5):617-25. discussion 26

22. Norton JA, Fraker DL, Alexander HR, Venzon DJ, Doppman JL, Serrano J, et al. Surgery to cure the Zollinger-Ellison syndrome. N Engl J Med. 1999;341(9):635-44. doi:10.1056/nejm199908263410902. 